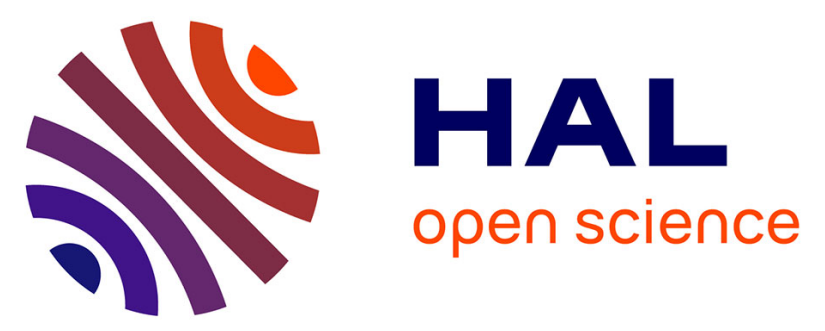

\title{
Mechanical behavior law of ceramic nanoparticles from transmission electron microscopy in situ nano-compression tests
}

Emilie Calvié, Julien Réthoré, Lucile Joly-Pottuz, Sylvain Meille, Jérome Chevalier, Vincent Garnier, Yves Jorand, Claude Esnouf, Thierry Epicier, J.B.

Quirk, et al.

\section{To cite this version:}

Emilie Calvié, Julien Réthoré, Lucile Joly-Pottuz, Sylvain Meille, Jérome Chevalier, et al.. Mechanical behavior law of ceramic nanoparticles from transmission electron microscopy in situ nano-compression tests. Materials Letters, 2014, 119, pp.107-110. 10.1016/j.matlet.2014.01.002 . hal-01137605

\section{HAL Id: hal-01137605 https://hal.science/hal-01137605}

Submitted on 10 May 2021

HAL is a multi-disciplinary open access archive for the deposit and dissemination of scientific research documents, whether they are published or not. The documents may come from teaching and research institutions in France or abroad, or from public or private research centers.
L'archive ouverte pluridisciplinaire HAL, est destinée au dépôt et à la diffusion de documents scientifiques de niveau recherche, publiés ou non, émanant des établissements d'enseignement et de recherche français ou étrangers, des laboratoires publics ou privés. 


\title{
Mechanical behavior law of ceramic nanoparticles from transmission electron microscopy in situ nano-compression tests
}

\author{
E. Calvié ${ }^{\mathrm{a}}$, J. Réthoré ${ }^{\mathrm{b}}$, L. Joly-Pottuz ${ }^{\mathrm{a}}$, S. Meille ${ }^{\mathrm{a}}$, J. Chevalier ${ }^{\mathrm{a}, *, 1}$, V. Garnier ${ }^{\mathrm{a}}$, Y. Jorand ${ }^{\mathrm{a}}$, \\ C. Esnouf ${ }^{\mathrm{a}}$, T. Epicier ${ }^{\mathrm{a}}$, J.B. Quirk ${ }^{\mathrm{a}, 2}$, K. Masenelli-Varlot ${ }^{\mathrm{a}, 1}$ \\ a INSA-Lyon, MATEIS UMR5510, 7 Avenue J. Capelle, 69621 Villeurbanne Cedex, France \\ ' INSA-Lyon, LaMCOS UMR5259, 7 Avenue J. Capelle, 69621 Villeurbanne Cedex, France
}

A methodology has been developed to determine constitutive laws of nanoparticles from in situ nano-compression experiments in a transmission electron microscope. It is based on image analysis to obtain relevant load-displacement curves, followed by finite element analysis associated to an inverse method. A transition alumina, stable only at the nanometer size, has been characterized as an example. The Young modulus and yield strength of this transition alumina, not available for such crystallographic structure, have been obtained.

\section{Introduction}

In materials science, a constitutive law describes the response of a material to an external solicitation. With the growing importance of nanotechnology in materials design and fabrication, access to constitutive laws at the nanoscale is a topical issue [1]. Several studies have dealt with the determination of the Young's modulus of nano-objects with high aspect ratios [2-5], eventually incorporating the yield or failure stress [6]. For example, plasticity could be observed in silicon, which is known to exhibit brittle behavior at the macroscopic scale [7]. In parallel, the development of in situ nano-indentation in TEM has been a major breakthrough, since it allows both local determination and the observation in real time of the nanoparticles' mechanical behavior [6-10]. However, no attempt was made to obtain their mechanical behavior constitutive law.

The plastic deformation of small commercial alumina nanoparticles has recently been reported [13]. Based on these observations, the objective of the present work was therefore to obtain constitutive laws from in situ nano-compression experiments in the transmission electron microscope (TEM) from image processing and load-displacement curves. The transition alumina nanoparticles are currently used for the fabrication of ceramic bulk materials. However, their mechanical properties remain unknown

\footnotetext{
* Corresponding author.

E-mail address: Jerome.chevalier@insa-lyon.fr (J. Chevalier).

${ }^{1}$ Member, Institut Universitaire de France.

${ }^{2}$ Now at Imperial College, London.
}

since the transition phases are not present in the sintered state and cannot be experimentally tested with conventional mechanical techniques.

\section{Materials and methods}

The commercial transition alumina powder (NanoTek ${ }^{\circledR}$, Nanophase Technologies Corporation, Romeoville, IL, USA) is produced by Physical Vapor Synthesis (PVS). It was dispersed in acidified water at $\mathrm{pH} 4$ using a $100 \mathrm{~W}$ ultrasound probe for $2 \mathrm{~min}$, in order to test particles individually $[14,15]$.

In situ nano-indentation tests were carried out using a dedicated straining sample holder from Nanofactory Instruments, fitted in a JEOL $2010 \mathrm{~F}$ microscope operating at $200 \mathrm{kV}$ accelerating voltage. The sample holder was equipped with a truncated diamond tip with a flattened area of about $500 \mathrm{~nm}^{2}$ and a load cell (maximum load of $3 \mathrm{mN}$ ). Particles were positioned on a sapphire substrate of $0.75 \mu \mathrm{m}$ thick, moving towards the tip during compression at a controlled displacement rate $(0.5 \mathrm{~nm} / \mathrm{s})$. Images of the experiment were directly recorded using a Gatan Orius 200 camera and video sequences acquired by the freeware CamStudio (v2.0, http://www.rendersoftware.com/products/camstudio).

The real displacement applied to the nanoparticle was determined by using Digital Image Correlation (DIC) from the experimental micrographs. By comparing two successive images, the displacement of the grey level transition at the boundary of the support and at the boundary of the tip was estimated. DIC usually allows arbitrary displacement fields to be estimated with a subpixel resolution (about 1/100 pixel), but in the present work only 

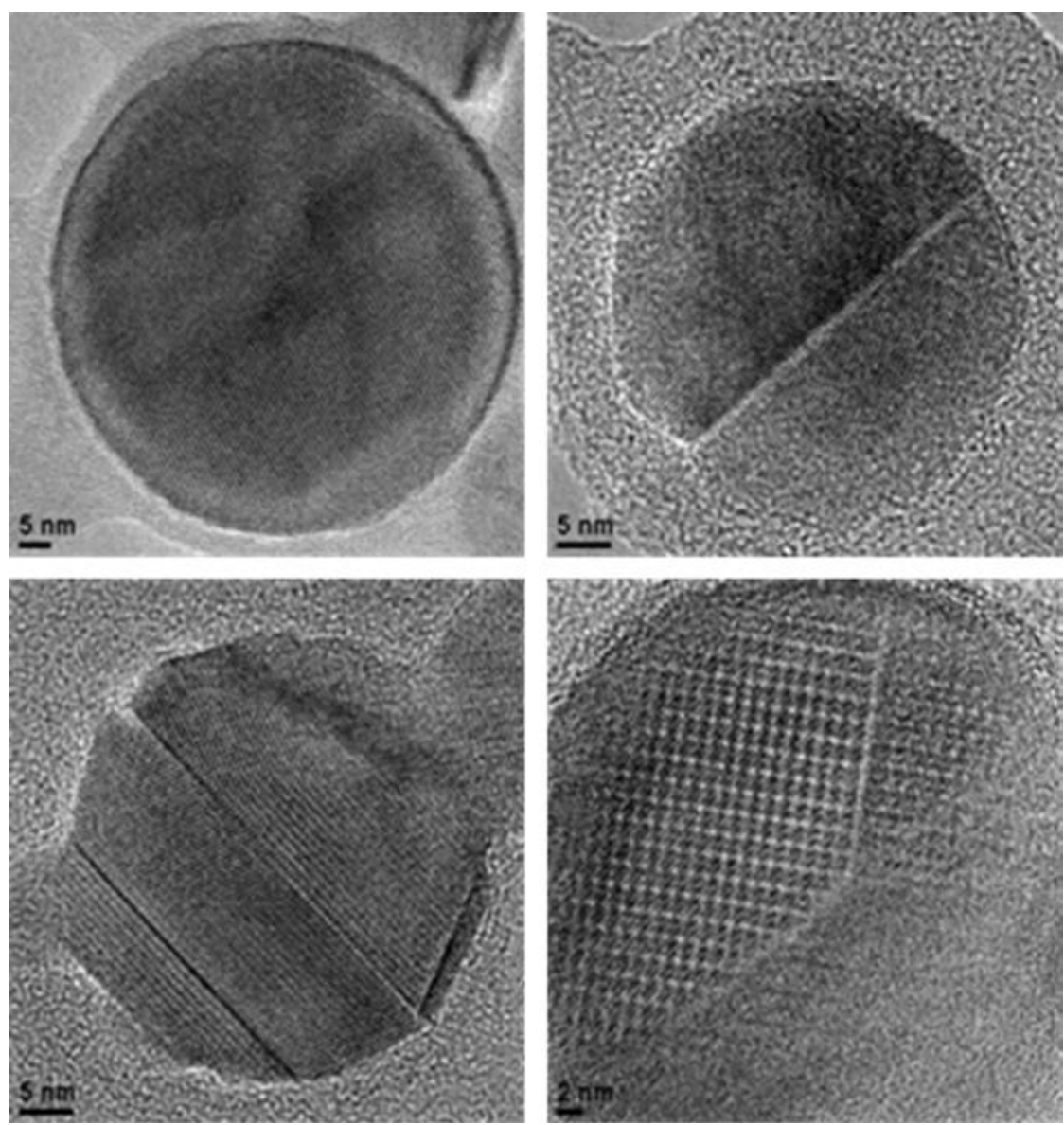

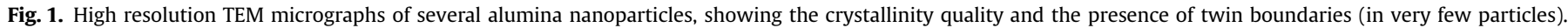

a rigid translation was searched for the measurement of this displacement; the actual displacement applied to the particle was obtained. Initially measured in pixels, this was further converted into nanometers by using the TEM scale bar.

Finite element (FE) simulations were performed using ABAQUS $^{\circledR}$ software. The initial particle was modelled as a sphere, its radius being estimated from the first image of the sequence. An axisymmetric model was built and the analysis accounted for geometrical non-linearities and contact with the tip and the support. Among the data available from the analysis, the reaction force for applying the displacement was extracted. Then, based on an inverse method, the parameters of the material constitutive model were adapted so that the reaction force matches the force measured during the experiment.

\section{Results and discussion}

Fig. 1 displays high resolution transmission electron micrographs of several nanoparticles. They are well crystallized, with eventually twin boundaries in very few of them. The indexation of the electron diffraction patterns revealed the presence of transition phases of $\mathrm{Al}_{2} \mathrm{O}_{3}$, namely $\delta$ (ICCD no. 16-0394) and $\gamma$ (ICCD no. 29-1486), with proportions of about 30 and 70 wt\%, respectively, in agreement with X-ray diffraction [11]. In order to preserve the integrity of the particles during exposure to the electron beam, no extensive electron diffraction work was performed before testing to identify their precise crystallographic nature, and characterize the twins possibly present. However, as twins are mostly observed in the biggest nanoparticles, and because we tested only perfect spheres, it is thought that the in situ nanoindentation experiments were carried out on nanoparticles without twins.

An experimental force-real displacement curve, recorded for a nanoparticle of $96 \mathrm{~nm}$ in diameter with compression of $50 \mathrm{~nm}$, is displayed in Fig. 2 (see Video 1, as Supporting information). We confirm the existence of plasticity at the nanoscale, even on a material exhibiting fragile behavior at the macro-scale. The parameters of a constitutive law have been extracted from the forcedisplacement curve using two different methods, namely an analytical one - using either the theory of a Hertz contact in a sphere-plane geometry for the load curve or the elastic response of a cylinder for the unload curve - and the inverse method described above.

Supplementary material related to this article can be found online at http://dx.doi.org/10.1016/j.matlet.2014.01.002.

In the case of DIC-FE analysis, the force-displacement curve was fitted up to the onset of strain localization. To obtain a satisfying fit between the computed and the measured forces, a Von Mises elastic-plastic model with linear isotropic hardening is used. The yield limit is thus a linear function (initial value $\sigma_{y}$, slope $H$ ) of the accumulated plastic strain. The constitutive model used herein thus involves four parameters: the Poisson ratio $\nu$ which has been fixed to 0.3 , the Young's modulus $E$, the initial yield stress $\sigma_{y}$ and strain hardening coefficient $H$. The Poisson's ratio was fixed to 0.3 , since this is a conventional value generally observed on crystalline solids. This is also roughly the value for bulk alumina. Moreover, its value had a negligible influence on the other, the most important parameters. $E, H$ and $\sigma_{y}$ are adjusted until a satisfying agreement between the experimental and the computed response is obtained, as illustrated in Fig. 2 and summarized in 


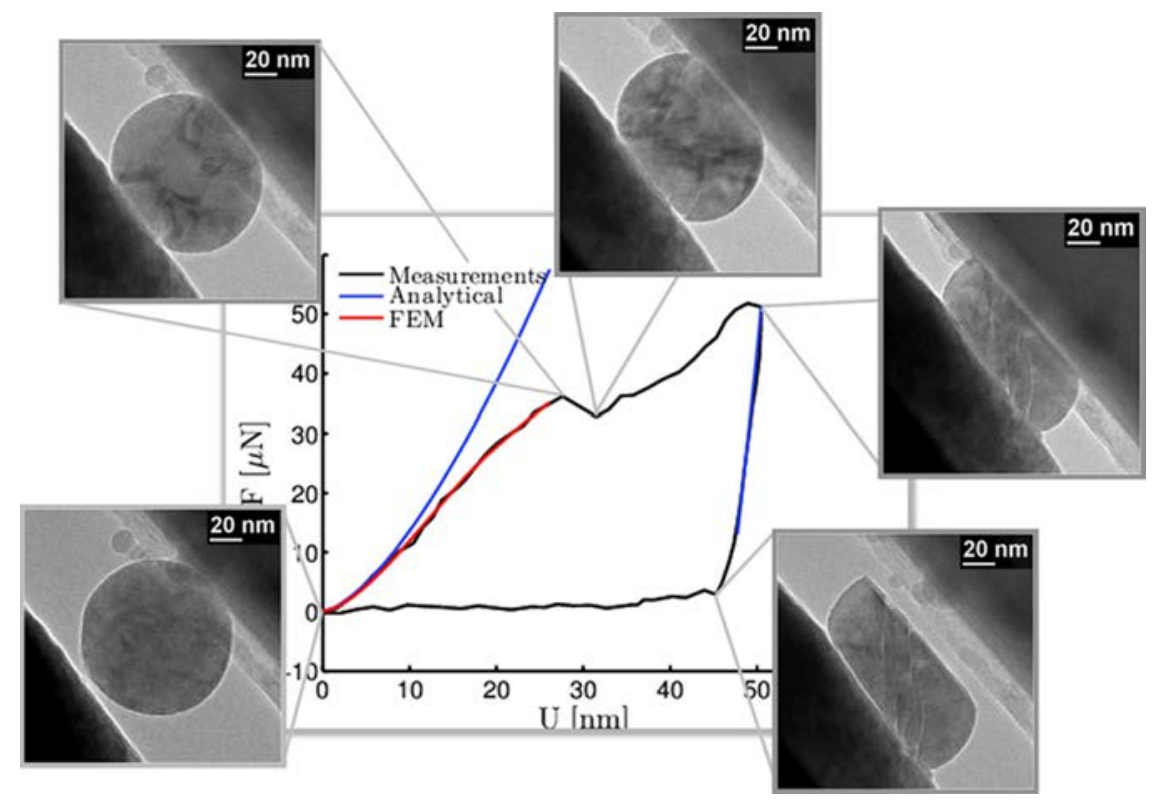

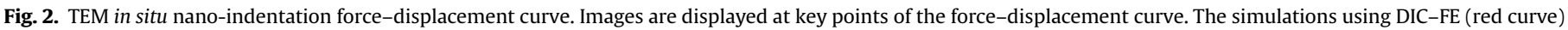

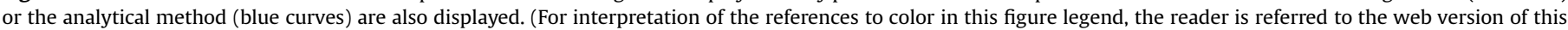
article.)

Table 1

Young's modulus $E$ and yield stress $\sigma_{y}$ derived from DIC-FE and from the analytical method. $H$ is equal to zero.

\begin{tabular}{|c|c|c|c|c|}
\hline \multicolumn{4}{|c|}{ Load curve } & \multirow{3}{*}{$\begin{array}{l}\text { Unload curve } \\
\text { Analytical } \\
\text { E (GPa) }\end{array}$} \\
\hline \multicolumn{2}{|l|}{ FEM } & \multicolumn{2}{|c|}{ Analytical } & \\
\hline $\boldsymbol{E}(\mathrm{GPa})$ & $\sigma_{\boldsymbol{y}}(\mathrm{GPa})$ & $\boldsymbol{E}(\mathrm{GPa})$ & $\boldsymbol{\sigma}_{\boldsymbol{y}}{ }^{\mathrm{a}}(\mathrm{GPa})$ & \\
\hline 115 & 10 & 113 & 8 & 113 \\
\hline
\end{tabular}

${ }^{a}$ Average contact pressure at the end of the elastic domain.

Table 1. The Young's modulus and the yield stress of the nanoparticle are equal to $115 \mathrm{GPa}$ and $10 \mathrm{GPa}$, respectively. Strain hardening can be considered as negligible. The excellent agreement with the values obtained from the analytical elastic model validates the DIC-FE procedure. It is noteworthy that the same constitutive law, namely a perfect elastic-plastic model with very similar values of $E$ and $\sigma_{y}$, has also been obtained from several experiments similar to the one described in the present figures. It should also be noticed that the value of $E$ and $\sigma_{y}$ found here for the nanoparticles cannot be compared with that corresponding to bulk alumina, since bulk alumina crystallises in a different form (the $\alpha$ phase) during sintering, which exhibits brittle behavior.

One of the major advantages of in situ nano-indentation in the TEM is the ability to observe the structural modifications inside the nanoparticle during the tests, which are revealed by diffraction contrasts. Clearly, for small loadings, Bragg fringes appear in the nanoparticle (see Figs. 2 and 3a), which are similar to those observed on other types of nanoparticles and possibly attributed to dislocations and elastic deformation [11,12]. In Fig. 3a, we present a superposition of the experimental image (deformation $39 \%$ ) with a map of the total equivalent plastic strain, calculated by FE simulations using the previously determined constitutive law. The contours of the maximum equivalent plastic strain have been highlighted. A good agreement between the experimental image and the calculated map indicates that the observed Bragg fringes are indeed the most probably caused by plastic deformation. The physical origin of plasticity in $\alpha$ alumina (obtained through nano-indentation tests on bulk samples for example) is generally associated to dislocations motion. Its origin in the present transition alumina is unknown and the current set of results does not allow to give a definitive physical interpretation. However, the elastic-plastic behavior law obtained through the inverse method is compatible with the most common plastic mechanisms by slipping. The theoretical shear strength of a single crystal without dislocation is given by $\tau_{E t h} \sim(E / 16)$. It would therefore lead to yield stress of $\sigma_{y t h} \sim(E / 8)$ for a Schmid factor of 0.5 . Given a Young's modulus of $115 \mathrm{GPa}$ as measured experimentally, this simple calculation would lead to a theoretical yield stress of $\sigma_{y t h} \sim 14 \mathrm{GPa}$, which is of the same order as the experimental yield stress measured experimentally $(10 \mathrm{GPa})$. At higher loadings, corresponding to approximately $45 \%$ deformation, damage occurs with the formation of tilted parallel lines, which can be regarded as cracks (see Fig. 3b). For a compressed sphere, fracture is expected to occur in brittle solids through a crack initiating at the center of the sphere - due to a tensile stress state - and propagating perpendicular to the compressed surfaces. This was observed in silicon nanospheres [10] of larger diameters (range of 170-250 nm). In our case, plasticity occurs almost in the whole nanoparticle and the stress reaches the yield stress within the plastic domain. Fig. $3 \mathrm{~b}$ displays both the experimental image and a calculation of the Tresca shear strain, just before the first crack appears. Parallel dashed lines indicate the observed direction of the first crack. The excellent agreement clearly demonstrates that the formation of cracks is governed by shearing, and that plastic deformation occurs well before fracture.

Knowing the mechanical behavior laws of nanoparticles may be of importance for phenomena such as third body wear particle in contact mechanics, milling of nanoparticles which may exhibit a plastic behavior below a certain size, or particle compaction during green body preparation of ceramics. It is for example usually considered that ceramic nano-powders just re-arrange without plastification during compaction. Fig. 4 shows a TEM image of a focused ion beam (FIB) thin section of a powder compact composed of the same transition alumina and pressed at ambient temperature under a pressure of $5 \mathrm{GPa}$. It definitively proves that plastification of ceramic nanoparticles can occur during compaction at ambient temperature. 

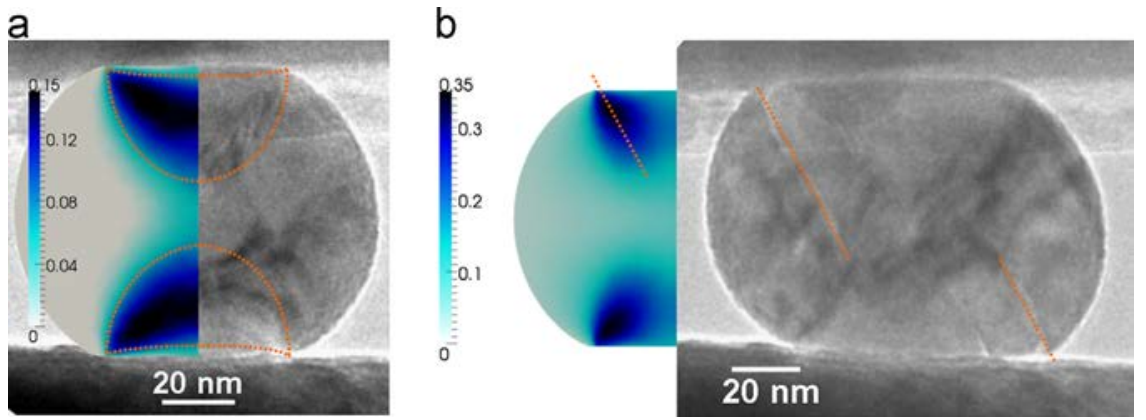

Fig. 3. (a) Superposition of an experimental image with the corresponding map of the total equivalent plastic strain calculated by DIC-FE, for the case of a $96 \mathrm{~nm}$ diameter nanoparticle. The contours of the maximum equivalent plastic strain are highlighted with dotted lines. (b) Superposition of an experimental image with the corresponding map of the Tresca shear strain calculated by DIC-FE, in the case of a $96 \mathrm{~nm}$ diameter nanoparticle. The direction of the first crack is indicated by a dotted line.

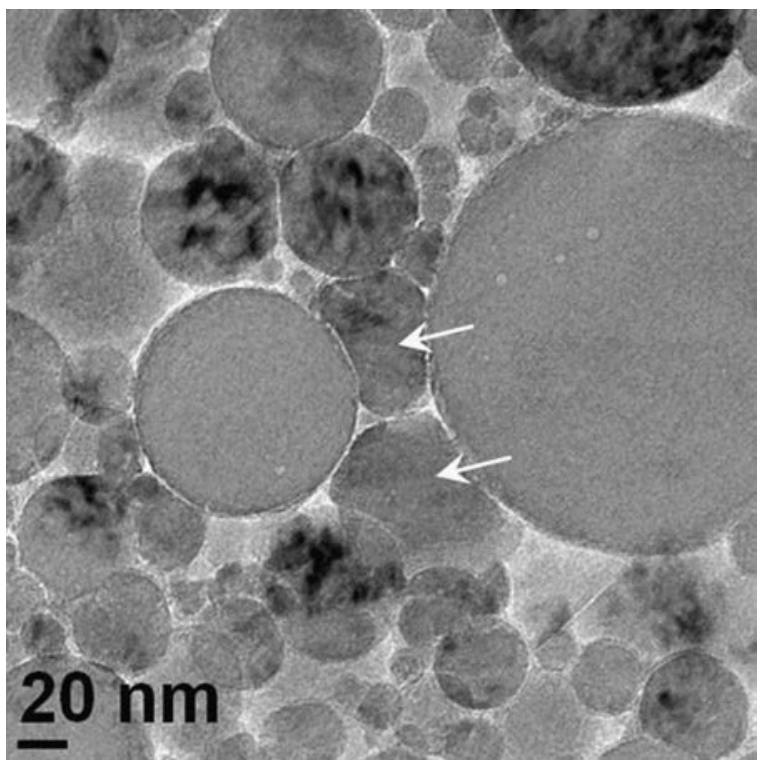

Fig. 4. TEM image showing plastic deformation of alumina nanoparticles in a powder compact during a pressing experiment at ambient temperature, under a pressure of $5 \mathrm{GPa}$. Arrows indicate nanoparticles highly deformed.

\section{Conclusion}

A constitutive law has been determined and values for the Young's modulus and the yield stress could be obtained for the nanoparticles. An example was given here on transition alumina nanoparticles. This methodology can be applied to any type of nanoparticles - regarding their composition and crystallography and can thus open new routes for the understanding and optimization of materials via a bottom-up approach.

\section{Acknowledgments}

Acknowledgments to the Centre Lyonnais de Microscopie (CLYM; http://www.clym.fr) for the access to the JEOL 2010F, to
Region Rhone-Alpes (Cluster MACODEV) and the Institut Universitaire de France for financial support, and Stephane Pailhes, ILM University Lyon, for the high pressure experiments.

\section{References}

[1] European second regulatory review on nanotechnology, 2012. Available at: 〈http://ec.europa.eu/nanotechnology/policies_en.html〉.

[2] Poncharal P, Wang ZL, Ugarte D, de Heer WA. Electrostatic deflections and electromechanical resonances of carbon nanotubes. Science 1999;283:1513.

[3] Löffler M, Weissker U, Mühl T, Gemming T, Büchner B. Robust determination of Young's modulus of individual carbon nanotubes by quasi-static interaction with Lorentz forces. Ultramicroscopy 2011;111:155.

[4] Bao L, Xu ZH, Li R, Li X. Catalyst-free synthesis and structural and mechanical characterization of single crystalline $\mathrm{Ca}_{2} \mathrm{~B}_{2} \mathrm{O}_{5} \cdot \mathrm{H}_{2} \mathrm{O}$ nanobelts and stacking faulted $\mathrm{Ca}_{2} \mathrm{~B}_{2} \mathrm{O}_{5}$ nanogrooves. Nano Lett 2010;10:255-62.

[5] Li R, Bao L, Li X. Synthesis, structural, optical and mechanical characterization of $\mathrm{SrB}_{2} \mathrm{O}_{4}$ nanorods. CrystEngComm 2011;13:5858-62.

[6] Arenal R, Wang MS, Xu Z, Loiseau A, Golberg D. Young modulus, mechanical and electrical properties of isolated individual and bundled single-walled boron nitride nanotubes. Nanotechnology 2011;22:265704.

[7] Stauffer DD, Beaber A, Wagner A, Ugurlu O, Nowak J, Mkhoyan KA, et al. Strain-hardening in submicron silicon pillars and spheres. Acta Mater 2012;60:2471.

[8] Minor AM, Syed Asif SA, Shan Z, Stach EA, Cyrankowski E, Wyrobek TJ, et al. A new view of the onset of plasticity during the nanoindentation of aluminium. Nat Mater 2006;5:697.

[9] Zheng K, Wang C, Cheng YQ, Yue Y, Han X, Zhang Z, et al. Electron-beamassisted superplastic shaping of nanoscale amorphous silica. Nat Commun 2010;1:24.

[10] Shan ZW, Adesso G, Cabot A, Sherburne MP, Syed Asif SA, Warren OL, et al Ultrahigh stress and strain in hierarchically structured hollow nanoparticles. Nat Mater 2008; 7:947.

[11] Deneen J, Mook WM, Minor A, Gerberich WW, Carter CB. In situ deformation of silicon nanospheres. J Mater Sci 2006;41:4477.

[12] Carlton CE, Ferreira PJ. In situ TEM nanoindentation of nanoparticles. Micron 2012;43:1134.

[13] Calvié E, Joly-Pottuz L, Clément P, Garnier V, Chevalier J, Jorand Y, et al. Real time TEM observation of alumina ceramic nano-particles during compression. J Eur Ceram Soc 2012;32:2067.

[14] Tang F, Uchikoshi T, Ozawa K, Sakka Y. Electrophoretic deposition of aqueous nano- $\gamma-\mathrm{Al}_{2} \mathrm{O}_{3}$ suspensions. Mater Res Bull 2002;37:653.

[15] Azar M, Palmero P, Lombardi M, Garnier V, Montanaro L, Fantozzi G, et al. Effect of initial particle packing on the sintering of nanostructured transition alumina. J Am Ceram Soc 2008;28:1121. 